\title{
Design Engineering - Not Just Applied Science
}

\author{
W. Ernst Eder \\ Royal Military College of Canada (retired) \\ Eder-e@kos.net
}

\begin{abstract}
Engineering has different aims to science. Science collects bodies of knowledge. Engineering provides processes and technical systems for specific tasks.

A main region of engineering is designing, with technical, economic, human, sociological and psychological dimensions. The scope of information for design engineering is broad - not just engineering sciences.

Types of products are needed to (a) compare design processes, and (b) to guide design education. Three action modes exist: (1) normal operation, (2) risk operation, and (3) safety or rational operation. (2) and (3) need guidelines and experience of systematic and methodical approaches, which must be learned before attempting to use them. A further problem of examinability arises.
\end{abstract}

\section{Introduction}

Engineering in general has aims that are different to science, the name alone indicates a part of that difference - 'engineering' implies a verb, an activity to produce something useful, 'science' implies a noun, a body of codified knowledge.

Science aims to collect and verify a body of knowledge, independent of its applicability for any task. Science investigates existing phenomena to obtain knowledge. A science is a system of knowledge, a structure that defines the elements and relationships, and a suitable arrangement of the information about a phenomenon. Knowledge (and science) is a sub-set of information. 'Science' is used as accumulated systematized knowledge, esp. when it relates to the physical world, and 'theory' denotes the general principles drawn from any body of facts (as in science) [Eder 2007, Hubka 1996].

Each science has an agreed boundary, preferably isolated so that the system is not influenced by interactions with other regions or phenomena. The science contains ordering characteristics, organization, categories, systematization, codification, records of structures of knowledge, theories and hypotheses about the region and its behaviors, including mathematical expression where possible, preferably published and peer-reviewed. Practical application is not a prior condition.

A science usually does not contain details and concrete expressions about practical applications. Based on the science, a theoretically useful way of classifying information from and for the practice can be shown, including information about a manifestation of the phenomenon that may be abstracted into the science. For instance, zoology states the taxonomy and the properties for recognizing that an animal should be given a particular (Latin) species name. That animal is not part of the science, it is a manifestation of the phenomenon that is abstracted into the science.

Engineering aims to provide processes and technical systems to solve a specific task, independent of the degree to which the applied phenomena are understood, especially in their interactions. The main regions of activity for engineering are designing, manufacturing and implementing, operating, procuring and supervising. Design engineering as an activity is probably least understood, its investigation only reaches back about 70 years [Eder 2007, Hubka 1996].

\section{Design Engineering - General}

Designing in engineering has technical, economic, human, sociological and psychological dimensions, see figure 1 .

The scope of information (including knowledge) needed for design engineering is of necessity very broad, see figure 2. It obviously includes the applicable engineering sciences. The need for connections, interactions and context of engineering science can be demonstrated on an example of thermodynamics - essentially expanding and compressing gases with heat and work addition and extraction. The connection to containment is usually not made obvious, but that containment needs strength at the prevailing temperature, possible guidance of flow (gas dynamics), etc. 
A)

Values in Technical Activities Effects of properties of TS(s) on other systems

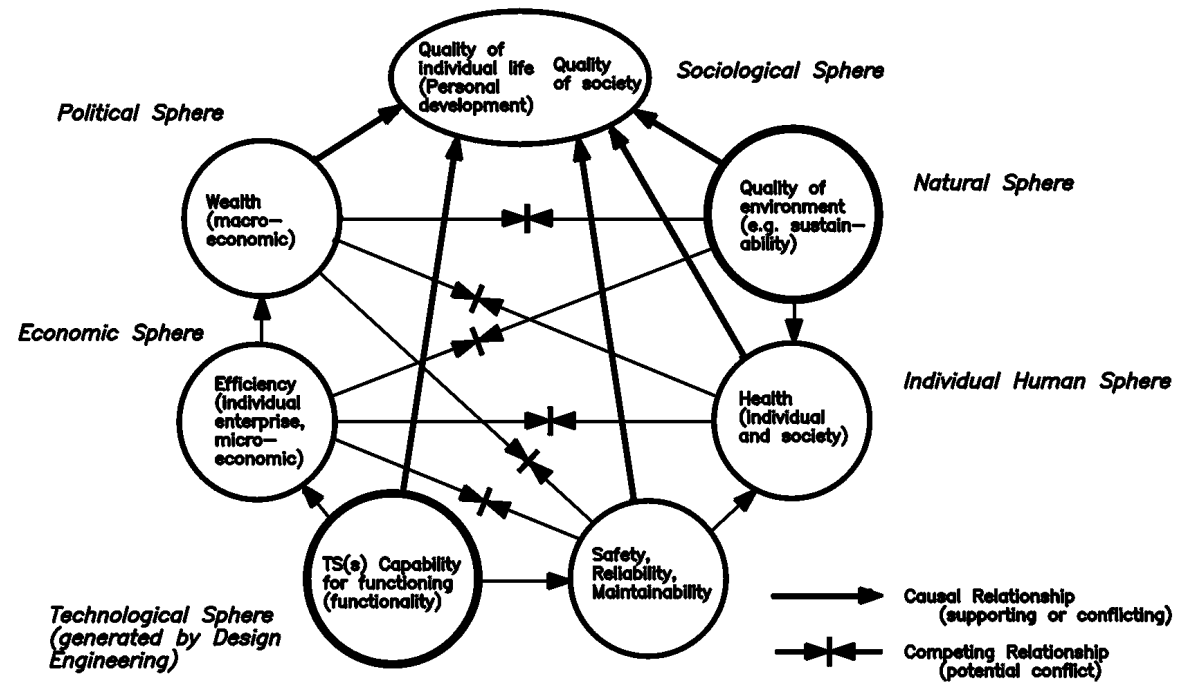

B) Centrality of Design Engineering in Context

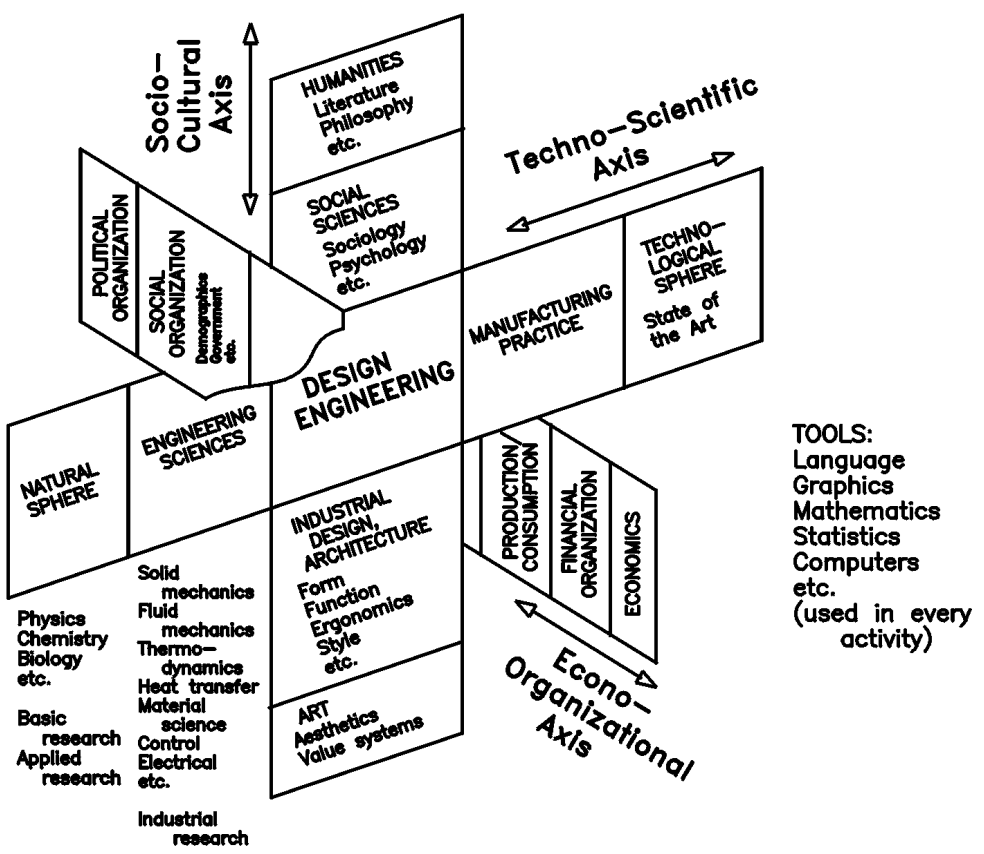

\section{Literature:}

Part A:

Ropohl, G. (1990) 'Die Wertproblematik in der Technik' (Value Problems in Technology), in Roozenburg, N. and Eekels, J., WDK 17 - EYAD - Evaluation and Decision in Desian Roozearg, Zürich: Heurista, $162-182$

-- VDI (2000) VDI Richtlinie 3780: Technikbewertung _- - Begriffe und Grundlage (Technology Part B:

Evaluation - - Terminology and Fundamentals), Düsseldorf: VDI-Verlag

Dixon, J.R. (1966) Design Engineering, New York: McGraw-Hill

Roseman, M.A. \& Gero, J.S. (1998) Purpose and Function in Design: from the Socio-Cultural to the Techno-Physical", Design Studies Vol. 19 No. 2, p. 161-186

Hundal, M.S. (1997) Systematic Mechanical Designing: a Cost and Management Perspective, New York: ASME Press

Figure EX-15

Figure 1. Role of Design Engineering in Context of Technology and Society [Eder 2007] 


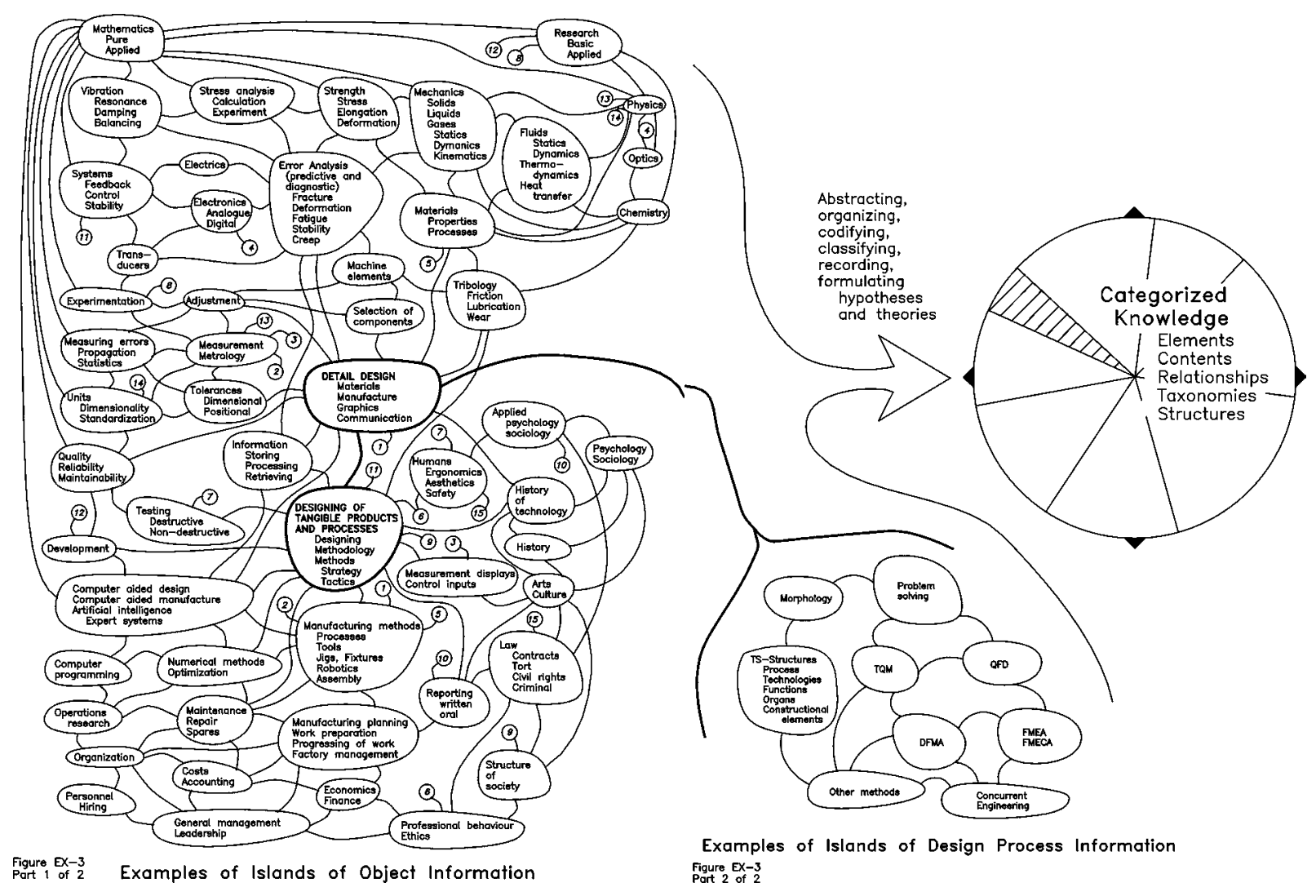

Figure 2. Transition from Scattered Information to Categorized Knowledge [Eder 2007]

Designing involves planning and executing (or having executed) an envisaged task, anticipating a future system, including writing, graphical work, products, etc. Art plays a role in engineering [Eder 2007, Hubka 1996].

An artificial system can be a 'process system' or a tangible 'object system'. These two terms need to be correctly understood:

! A process $(\mathrm{P})$ is a change, procedure, course of events, taking place over a period of time, in which an object transforms, or is transformed, from one state to a preferably more desirable different state, generally called a transformation process (TrfP). The smallest convenient steps in a process are called operations. Examples are crushing seeds to extract oil, transporting a load from one place to another, building a bridge, recording information, etc.;

! An object system is a tangible, real, material entity.

! A technical process (TP) is that part of a transformation process (TrfP) performed mainly by or with the help of outputs (effects) delivered by a technical system (TS).
! A technical system (TS) is an artificial object system with a substantial engineering content, which is capable of solving or eliminating a given or recognized problem, i.e. providing effects (at a particular time) to operate a process. A TS consists of constructional parts and their relationships. Examples are a car manufacturing facility (industrial plant), a car (machine), a motor (engine) in that car (machine or assembly group, or module), a connecting rod assembly in that motor (assembly group, or module), a threaded stud in the connecting rod assembly (constructional part), a building, etc.

Both 'process systems' and 'object systems' interact and must cooperate in a transformation system, see figure 3 , and should therefore be designed together. Manufacturing processes are a particular kind of process system, in which an information system (IS) is a direct executing operator of the process, giving specifications of what is to be made, quantities, etc.

'Designing' should be distinguished from a 'design process'. 'Designing' implies that humans are the only operators performing the process. Yet designers use tools, knowledge of various kinds, and external 
representations, and are subject to management, and their environments. 'Design process' is more suitable for these transformation processes. 'Design engineering' and 'engineering design process' should be used where the product is a technical system, TS(s), and/or technical process, TP(s). The addition of '(s)' signifies that the TP and/or TS is the subject of the design process. Human cognitive abilities and skills (latent and developing) are essential, a computer alone cannot design. Some artificial intelligence techniques can almost complete designing for some TS (e.g. VLSI electronic chips).

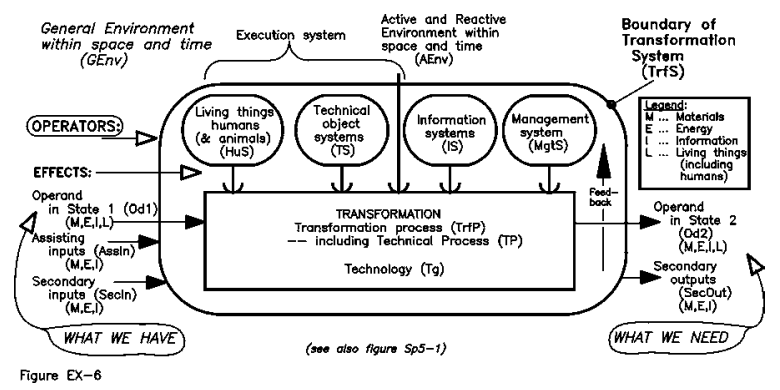

Figure 3. General Model of the Transformation System [Eder 2007]

Designing in engineering has the purpose of creating future operating artifacts (TS), and the operational processes (TP) for which they can be used, to satisfy the needs of customers, stakeholders and users. These artifacts may be able to actively operate, or to be operated as a tool by a human being. This purpose is accomplished by designing suitable technical means (TP and/or TS), and producing the information needed to realize and implement a product. Designing something useful with a substantial engineering content, usually within market constraints, distinguishes engineering from scientific or artistic activity. Therefore design engineering, combining art, craft and science, is the activity and subject of this paper.

Design engineering explores alternative solution proposals, and delivers proposals for appearance and presence, and/or manufacturing specifications for a designed product. Architecture, styling or industrial design are not specifically included as customers for systematic design processes, except where they influence design engineering. A substantial difference exists between artistic designing and design engineering, yet both have much in common.

The scope of information (including knowledge) needed for design engineering must also include a wide range of non-scientific information, including experience heuristics, proprietary information, management, socio-technical, political, economic, and many other aspects. Designing engineers also need a broad connectedness of these many classes of information, at least to the level of awareness.

The output of Design engineering is a set of manufacturing drawings for constructional parts (or their computer-resident equivalents), assembly drawings, and parts lists. Documentation is needed to demonstrate that performance, strength and durability have been considered, usually by engineering science analysis. For novel design engineering, more abstract elements and structures are usable - transformation processes, technologies, functions, and organs [Hubka 1988a, 1992, and 1996; Eder 2007]. Creativity also has a role [Eder 1996], but systematic and methodical designing is preferable [Eder 2007, Hubka 1996]. Industrial design and design engineering must frequently be coordinated.

\section{Products}

A rough definition of types (sorts) of products is needed [Eder 2003, 2006a and 2006b] in order to (a) compare types of design processes (processes that are intended to create the manufacturing and/or implementation instructions for a product) and to investigate their scope, and (b) to give some guidelines for design education in various disciplines. 'Products' according to [ISO 9000:2000] are 'results of a set of interrelated or interacting activities which transform inputs into outputs', and include 'services', 'software', 'hardware', and 'processed materials', also known as goods and services, or as artifacts and processes. Some of these have a substantial contribution from engineering, technical systems and technical processes [Hubka 1988a and 1996, Eder 2007].

A (non-linear, branched) 'scale' of artifacts begins at artistic works. Consumer products are consumable items and materials. Consumer durables have appropriate appearance and operability, project the 'right' image, and perform useful tasks at a suitable cost. Bulk or continuous engineering products act as raw materials for other manufacture. Industry products are bought by a manufacturing organization for assembling into their own products. Industrial equipment products are self-contained devices which perform more or less complex functions. Special purpose equipment, include jigs, tooling, fixtures, and specialized manufacturing machines, robotics, handling and packaging machines, but also oceangoing ships and buildings for which appearance is very important. Industrial plant usually consists of industrial equipment products, and devices to control and/or connect them. Configuration products are items 
of equipment and/or industrial plant for which the parts are quantity-produced and standardized industrial equipment products (OEM, COTS) designed as modular interchangeable technical systems, which are assembled to the customers' requirements with little further modification.

Designing in most cases involves a re-design of a previous product, and can range from innovative to routine. In some cases, a previous product does not exist, or must be altered so radically that a novel design process is more appropriate. Designing is an essential part of integrated product development, but these two concepts do not coincide.

\section{Design Engineering - Systematic And Methodical Procedure}

The model of an ideal systematic and methodical procedure is based on Engineering Design Science [Eder 2007, Hubka 1996], and supporting literature [Hubka 1976, 1978, 1988a, 1988b 1992, Eder 1992, 1996]. Systematic design engineering is the heuristicstrategic [Koen 2003] use of a theory to guide the design process. Methodical design engineering is the heuristic use of newly developed and established methods in engineering design, including theory-based and 'industry best practice', strategic and tactical, formalized and intuitive methods.

The start of the procedural model, figure 4 , is an origin of a design problem, either product planning for an organization, or assignment of a problem from management to a design section. The proposed solution (preferably in manufacturable or implementable detail) is the output of a transformation process: 'design engineering', see figure 5. This ideal procedure needs to be adapted to the actual problem and situation.

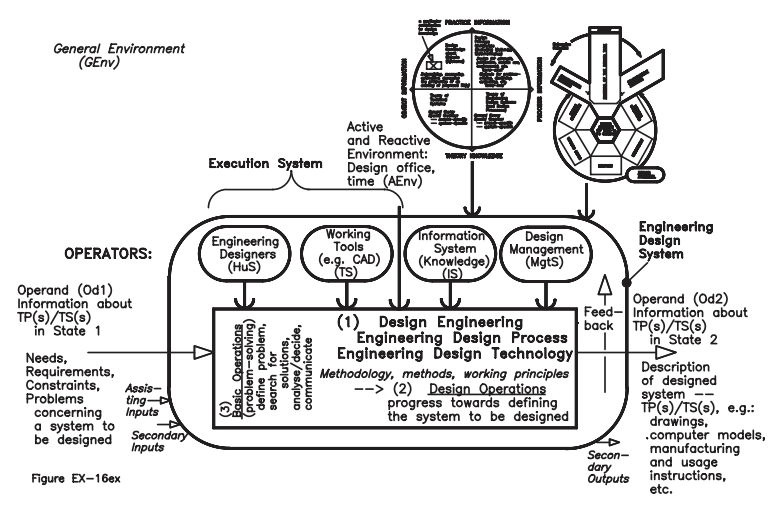

Figure 5. Model of the Engineering Design Process and Engineering Design System [Eder 2007]
Usual in many organizations is a premature entry into a design problem, in most cases the problem statement 'as given' is accepted without critical review - the problem is 'understood' without real clarity or definition. For example, the stated requirement is for a milling machine, lawn mower, electrical transformer. A more abstract formulation would be of transformation of raw material to a usable part, cutting grass, or changing the voltage of an electricity supply. Yet all design work should start by clarifying the design problem, especially with respect to customers' real needs and wishes, economics, environmental and life-cycle impacts, etc. [Feilden 1963].

Once the problem is clarified, the majority of design problems are entered at a more concrete stage than 'conceptualizing', typically with requirements for functioning [Eder 2005b, 2006a and 2006b]. The 'problem as given', and therefore the design task deals with an existing product 'line', a TS-'sort', for which conceptualizing (and the more abstract forms of modeling) can be limited, or is not used - the organ structure for a particular TS-'sort' remains constant, i.e. the relevant models of (e.g.) transfor-mation processes and functions remain unaltered.

The complete 'top-down' procedure, and generating models of more abstract structures of a TP(s) and/or $\mathrm{TS}(\mathrm{s})$ can be important if a radically new solution should be found. The question 'Why wash clothes?' may lead to the concept of disposable clothing as a radical solution for a specialized problem situation with environmental consequen-ces. Stepping back into the abstract, 'bottom-up', can be useful for organs parts of a system where inno-vation shows promise, mainly for (recursively sepa-rated) design groups, subassemblies or mechanisms.

One problem concerns industries - design engineering is often regarded as an accounting 'overhead'. Parallel to the efforts to scientifically investigate design engineering, many industrial organizations discovered the core importance of design engineering for their survival and financial health. In the English-language regions the emphasis was on 'industrial design', correcting the appearance and ergonomics of TS. A systematic and theory-based coverage of all necessary properties, using consistent models of the concepts and methods, is still to be accepted [Eder 2006a and 2007].

Change is not easy. Unless advantages are seen, and changes are actively demanded, engineering designers have little incentive to change. Introducing the presented theoretical, methodical, heuristic and experience information into an organization can and should be done in small steps. 


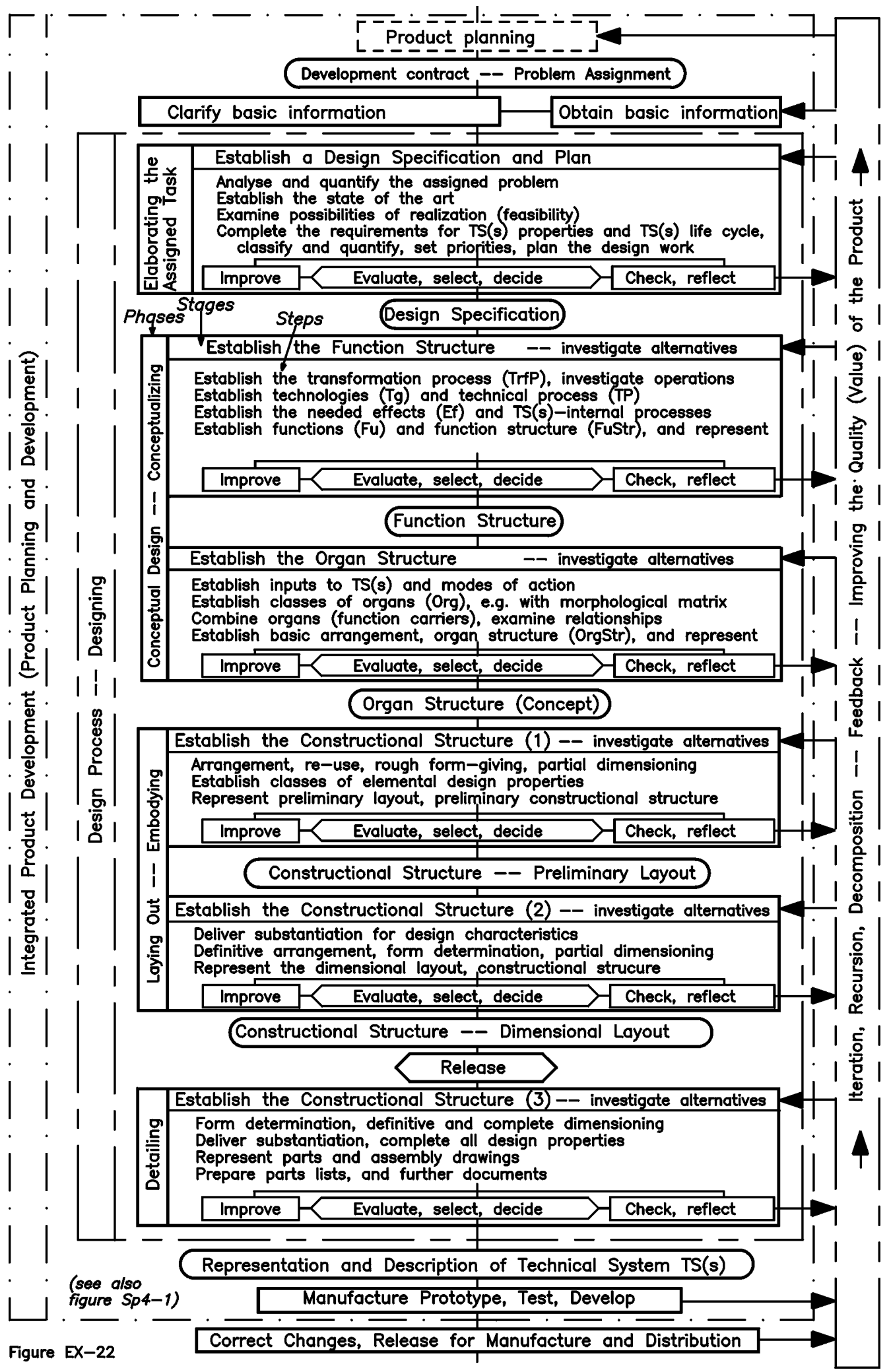

Figure 4. General Procedural Model of the Engineering Design Process [Eder 2007] 


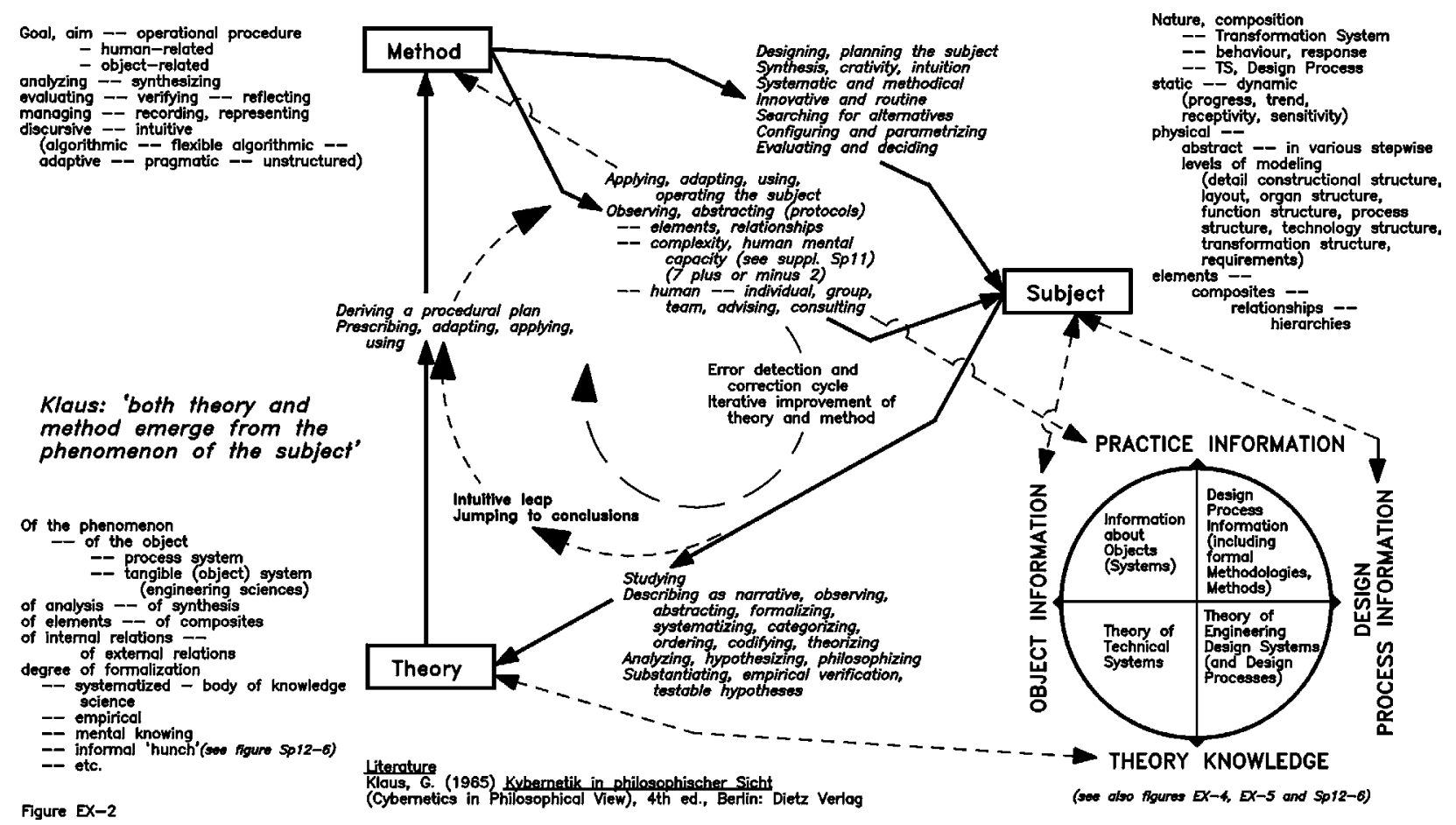

Figure 6. Relationship Among Theory, Subject and Method [Eder 2007]

The system of EDS [Eder 2007, Hubka 1996] is significant. The concept of the system is based on the triad 'subject - theory - method', i.e. a theory about a subject allows a method to be defined and heuristically applied, for using or for designing the subject, see figure 6 . The system is focused on design engineering of technical processes (TP $=$ TS-operational process) and/or technical systems (TS), and includes design engineering information about TP and TS, and engineering design processes.

\section{Design Engineering - Action Modes}

In designing, the engineering principle [Müller 1990]) states that: Engineering designers should produce their proposals only as accurately and completely as necessary, but also as coarsely, crudely and applicably as possible to achieve the necessary accuracy and completeness. This is the normal working mode of engineering designers, who mostly work on a project close to the deadline. This leaves little time to complete the project, search for alternatives, optimize, or reflect. A first idea is carried through until an acceptable solution is found, or the project is terminated - 'satisficing' [Schön 1983, 1987]. If a project is started when it is received, the sub-conscious mind can work on the problems, using incubation [Wallas 1926]. Systematic work demands early starting, and consistent steady working.

Engineering designers must take responsibility for proposals, but should not perform work beyond the state of confidence. Designing must be ended when the proposals can be accepted in the situation, optimal in principles, layout, embodiment and detail. The risk in this procedure must be accepted by the designers, with a realistic view of their capabilities.

Design engineering [Müller 1990], consists of anticipating a possible change based on a future implementation of a TP(s)/TS(s). Designing depends on available information and theory about systems [Eder 2007; Hubka 1988a, 1992 and 1996] and about designing [Eder 2007; Hubka 1992 and 1996]. The products of design engineering are proposals. These cannot be evaluated as 'true' or 'false', or 'probable' or 'improbable', they can only be evaluated and simulated as realizable or not, and valued better or worse than competing proposals.

Design engineering can only result in sufficiently complete and reliable information about the anticipated TP(s)/TS(s) if the designers can be sure to have considered all factors [Eder 2006a and 2007]. Then, an anticipating proposal (and its documentation) for a designed TP(s)/TS(s) can be evaluated as technically accomplishable, if it can be confirmed with sufficient credibility and confidence that: (a) the TS(s) will fulfill the requirements under the 
circumstances of operation with sufficient reliability; (b) it is implementable or manufacturable under the given circumstances; (c) it complies sufficiently with the requirements of the manufacturing processes; and (d) all other requirements are fulfilled in acceptable ways to the user, customer, organization, legal and political authorities, the economy, culture, environment, etc.

Then also, an anticipating proposal (and its documentation) for implementing a TP(s) and/or manufacturing a TS(s) can be evaluated as technically realizable, if it can be confirmed with sufficient credibility and confidence: (a) that it can be implemented and/or manufactured under the given circumstances; (b) that the proposed sequence of implementing and/or manufacturing operations as specified will fulfill the required purposes of the TP(s)/TS(s) with sufficient reliability; and (c) that the requirements of the field are acceptably fulfilled.

To verify the accomplishability and realizability, the proposals must be tested in a design audit, by experiments, simulations, models, samples and prototypes of the complete system and/or of suitable parts. Proposals should be confirmed before release for manufacture or implementation.

The engineering principle [Müller 1990] must be tempered by a human trend to over-estimate one's own capabilities and knowledge - over-confidence. Over-confidence seems to be prevalent when defining design tasks - designers (even though their preparation is not adequate) frequently think they understand the problem.

For design engineering, three kinds of action modes exist [Müller 1990]: (a) Normal operation (intuitive, second nature procedure) runs activities from the subconscious in a learned and experienced way, at low mental energy, giving an impression of competence [Pahl 1994a and 1994b]. If difficulties arise, the action departs from the normal, and higher energy is needed. (b) Risk operation uses the available experiences (and methods) together with partially conscious rational and more formalized methods, in an unplanned trial and error behavior, which can occasionally be very effective. (c) Safety or rational operation needs conscious planning for systematic and methodical work, with conscious processing of a plan, because competence is in question.

Both risk operation and safety/rational operation need guidelines and learning/experience of systematic and methodical approaches, preferably based on a coherent and complete (but not necessarily mathematical) theory [Eder 2007, Hubka 1996]. This systematic and methodical working mode must be learned before attempting to use it, preferably in

\section{the 'safe' environment of an educational institution.}

Normal, routine, operation is mainly preferred and carried out by an individual. Risk operation tends to demand team activity, the task becomes non-routine, consultations can and should take place - 'bouncing ideas off one another', obtaining information and advice from experts [Ahmed 2004], reaching a consensus on possibilities and preferred actions, etc. Consultations are best if the participants are of approximately equal experience or status, or if there is a large gap in experience from questioner to consultant. Personal contact tends to be quicker at lower mental energy than obtaining information from (written) records [Ahmed 2004, Pahl 1994b].

Non-routine situations often produce critical situations in a design process [Frankenberger 1997a, 1997b, 1997c and 1998], e.g. during: (a) defining the task, analysis and decisions about goals; (b) searching for and collecting information; (c) searching for solutions; (d) analyzing proposed solutions; (e) deciding about solutions; (f) managing disturbances and conflicts, individual or team. When a method is well known to the designer, it can at best be run from the sub-conscious, and the users can then even deny that they are using the method. It is necessary for engineering designers to learn methodology during their engineering education. Then the methods are familiar enough to apply, even if there is resistance from a supervisor. The beneficial results of teaching design methodology have been demonstrated [Dörner 1995, Fricke 1991, Günther 1997, Pahl 2007], after 25 years of teaching, and after some graduates entered industry as engineering designers in responsible positions.

\section{Teamwork}

Design engineering is rarely the work of an individual, several to many people must cooperate, preferably using the methods and attitudes of teamwork [Eder 2007], and a common language including models and methods. This, too, should be learned before the need for application arises. It includes methods of conflict resolution. Whilst team cooperation is important, it is merely one of many factors influencing design engineering.

The proportion of systematic, methodical work should be increased, especially for team consultations. This methods-conscious mode of working, and the appropriately documented results, should be demanded by higher management. 


\section{Acceptance}

Acceptance of methods in industry has been low, and tends towards application of simplistic procedures. Only when a sufficient number of educated practitioners enter the field can improvement for risk and safety operation be expected. This also requires acceptance of designing as a discipline of engineering, preferably based on a coherent theory and context [Eder 2007, Hubka 1996].

Acceptance for methods was explored by Müller [Eder 1996, Müller 1994, Pahl 1994b], and depends on many psychological elements. People rarely depart from experiences and learned (intuitive) methods, the 'unknown' displays dangers and risks. The difficulty and time needed for learning an approach leads initially to reduced performance, and the later increase may not be obvious. Learning methods under stress is poor motivation to good performance. Methods need more mental energy, but can expand the solution field. Methodology does not restrict creativity, only negative attitudes to method can negatively influence creativity.

Acceptance Barriers exist for systematic procedures. It may be surprising that industry has not yet accepted the newer methods (including EDS [Eder 2007, Hubka 1996]), and generally does not even know about them [Pahl 1994b; Müller 1991 and 1994; Eder 1998; Frost 1999; Fulcher 1996; Sheldon 1997]. The term Engineering Design Science is generally mis-understood. Yet the methods that industry does accept and use (e.g. TQM, QFD, Taguchi, etc.) are claimed as 'industry best practice', and industry wants academia to accept these methods. An explanation for this delay in accepting 'foreign' results (in both directions) is needed. Unfamiliar terminology, outside ones own experience, and use of familiar words in a different context make the transition more difficult.

Even the individual 'industry best practice' methods are each used in only a small fraction of industry. Methods tend to be more useful for clarifying problems, and for conceptualizing solution proposals, in which active creativity may be essential. For embodying and elaborating, creativity is less essential, and more experience information is required, although many innovations can be implemented at this level.

Members of an organization must have 'ownership' of the method, and adapting and championing a method is a difficult task for which time is usually not available. Unless a visible success is attained in the first few attempts at usage, the method is likely to fall into disuse almost immediately. Champions emerge when economically or politically powerful bodies ask for action: top-level executives, selling organizations (e.g. the 'industry best practice' methods), standards
[ISO 9000:2000] and [ISO 14000:1995], or by setting requirements.

When engineering designers meet a novel problem outside their immediate experience, more formal procedures and methods are needed. Such methods must usually be known in advance of the need to use them. Learning 'on the job' is difficult, unless it is supported by management. A good understanding of the method and its underlying theory is important for theory-based methods. Then the procedure that is prescribed or recommended for the method makes more sense, therefore producing less stress, and a better direction towards the goals.

\section{Academic Considerations}

A combined systematic approach to designing is recommended, using appropriate methods and intuitive working. This should be the aim in the educational program for all engineers. Education for design engineering needs particular attention to pedagogics and didactics [Eder 2005a], the strategies and tactics of inducing learning relevant to the object information and the design process information needed for risk and rational operation.

Attention should also be given to the aspect of transferability [Pahl 1996], enabling students to transfer the experiences from one (isolated) course to all others, and to correlate and cont4extualize their studies.

A model curriculum has been proposed [Eder 2001]. The first-year presentaton should start to introduce the concepts of Engineering Design Science [Eder 2007, Hubka 1996], but concentrate on designing in routine situations, especially on redesigning existing items of engineering products. From second year onwards, the emphasis should move towards risk and rational operation, completing the concepts of Engineering Design Science, and involving risk and rational operation with increasingly more complex problems of design engineering. A final-year project should demand full use of the recommended procedural model and method, augmented by other methods where applicable.

For academic purposes, a further problem of examinability arises. When a method is well learned, it tends to be used from the subconscious, in an intuitive manner which the user can hardly describe. Examination is possible when the methods are first learned.

Students also need to be made aware of the history of technology (e.g. [Billington 2001 and 2006]), how 'their' specialized field developed over the centuries, 
and of any dangers involved in radical change or disruptive technologies [Christensen 1997].

One to two human generations are needed for a new insight (a change in the disciplinary matrix, a paradigm shift) to be generally accepted [Kuhn 1970 and 1977]. There is always resistance to change, and to accept good points from other schools of investigation, especially if the expected leap is large [Müller 1991 and 1994].

\section{Closure}

Design engineering is such an important element of human activity, that it should feature in all years of study in engineering education. Systematic and methodical working to enable creativity should be learned in a relatively 'safe' environment, before any situations of risk or rational operation arise. The understanding delivered by EDS as basis should also help to coordinate the subjects in a curriculum.

\section{0, References}

Ahmed, S. and Wallace, K. (2004) 'Identifying and Supporting the Knowledge Needs of Novice Designers within the Aerospace Industry', Jnl. Eng. Design, Vol. 15 No. 5, p. 475-492

Billington, D.P. (2001) The Innovators, New York: Wiley Popular Science

Billington, D.P. and Billington, D.P., Jr. (2006) Power, Speed, and Form, Princeton, NJ: Princeton University Press

Christensen, C.M. (1997) The Innovator's Dilemma: When New Technologies Cause Great Firms to Fall, Boston, MA: Harvard Business School Press

Dörner, D., Ehrlenspiel, K., Eisentraut, R. and Günther, J. (1995) 'Empirical Investigation of Representations in Conceptual and Embodiment Design,' in Hubka, V. (ed.) (1995) WDK 23 - Proc. International Conference on Engineering Design - ICED 95 Praha, Zürich, Heurista, p. 631-637

Eder, W.E., Hubka, V., Melezinek, A. and Hosnedl, S. (1992) WDK 21 - ED - Engineering Design Education - Ausbildung der Konstrukteure Reading, Zürich: Heurista

Eder, W.E. (ed) (1996) WDK 24 - EDC - Engineering Design and Creativity -- Proceedings of the Workshop EDC, Pilsen, Czech Republic, November 1995 Zürich: Heurista

Eder, W.E. (1998) 'Design Modeling - a Design Science Approach (and Why Does Industry Not Use It?)', Jnl Eng Design, Vol 9, No 4, p. 355-371

Eder, W.E. and Hubka, V. (2001) 'Curriculum, Pedagogics, and Didactics for Design Education', in (2001) WDK 28: Proc. International Conference on Engineering Design, ICED01 Glasgow, 21-23 August 2001, London: IMechE., Vol 4, p. 285-292
Eder, W.E. (2003) 'A Typology of Designs and Designing', in DS 31 - Proc. ICED 03 Stockholm, p. 251-252 (Summary), paper 1004 on CD-ROM, The Design Society

Eder, W.E. (2005a) 'Survey of Pedagogics Applicable to Design Education: An English-Language Viewpoint', Int. Jnl. Eng. Education, Vol 21, No 3, p. 480-501

Eder, W.E. (2005b) 'Application of Design Methodology for Education' in Proc. Second CDEN International Conference, University of Calgary, Alberta, 18-19 July 2005 at Kananaskis Resort, paper 10007 on CD-ROM

Eder, W.E. (2006a) 'Properties of Technical Systems - Key to Crossing Design Boundaries', in Proc. CDEN Conference 2006, paper 10021

Eder, W.E. (2006b) 'Case Study in Design Engineering', in Proc. CDEN Conference 2006, paper 10028

Eder, W.E. \& Hosnedl, S. (2007) Design Engineering: A Manual for Enhanced Creativity, Boca Raton: CRC Press (in press)

Feilden, G.B.R. (1963) Engineering Design, Report of Royal Commission, London: HMSO

Frankenberger, E., Badke-Schaub, P. and Birkhofer, H. (1997a) 'Factors Influencing Design Work: Empirical Investigations of Teamwork in Engineering Design Practice', in Riitahuhta, A. (ed.) (1997) WDK 25 Proc. ICED 97 Tampere, Tampere University, p. 2/387-392

Frankenberger, E. and Badke-Schaub, P. (1997b) 'Integration of Group, Individual and External Influences in the Design Process', in Frankenberger, E., Badke-Schaub, P. and Birkhofer, H. (eds.), Designers: The Key to Successful Product Development, Berlin/Heidelberg: Springer-Verlag, 1997

Frankenberger, E. (1997c) Arbeitsteilige Produktentwicklung (Product Development with Task Distribution), Fortschrittsberichte VDI Reihe 1, Nr. 291, Düsseldorf: VDI

Frankenberger, E. and Badke-Schaub, P. (1998) 'Role of Critical Situations in Design Processes and Education', in Proc. WDK International Workshop PDE Pedagogics in Design Education, Pilsen: West Bohemia University, 1998

Fricke, G. and Pahl, G. (1991) 'Zusammenhang zwischen Personenbedingtem Vorgehen und Lösungsgüte' (Relationship between Personally Conditioned Procedure and Quality of Solution), in Hubka, V. (ed.) WDK 20: Proc. of ICED 91 Zürich, Zürich: Heurista, 1991, p. 331-341

Frost, R.B. (1999) 'Why does Industry ignore Design Science?', Jnl. Eng. Design, Vol. 10 No. 4, p. 301-304

Fulcher, A.J. and Hills, P. (1996) 'Towards a Strategic Framework for Design Research,' Jnl. Eng. Design, 7 No. 2, p. 183-194

Günther, J. and Ehrlenspiel, K. (1997) 'How Do Designers from Practice Design?' in Frankenberger, E., BadkeSchaub, P. and Birkhofer, H. (eds.) (1997) Designers: The Key to Successful Product Development, Berlin/Heidelberg: Springer-Verlag, p. 85-97, 1997

Hubka, V. (1976) Theorie der Konstruktionsprozesse (Theory of Design Processes), Berlin: Springer-Verlag 
Hubka, V. (1978) Konstruktionsunterricht an Technischen Hochschulen (Design Education in Universities), Konstanz: Leuchtturm Verlag

Hubka, V., \& Eder, W.E. (1988a) Theory of Technical Systems, New York: Springer-Verlag, completely revised translation of Hubka, V. (1984) Theorie Technischer Systeme (2 ed, revised from Theorie der Maschinensysteme 1974), Berlin: Springer-Verlag

Hubka, V., Andreasen, M.M. and Eder, W.E. (1988b) Practical Studies in Systematic Design, London: Butterworths (English edition of WDK 4 Fallbeispiele, Zürich: Heurista, 1981 and 1983)

Hubka, V., \& Eder, W.E. (1992) Engineering Design, Zürich: Heurista, $2^{\text {nd }}$ edition of Hubka, V. (1982) Principles of Engineering Design, London: Butterworth Scientific, translated and edited by W.E. Eder from Hubka, V. (1980) WDK 1 - Allgemeines Vorgehensmodell des Konstruierens (General Procedural Model of Designing), Zürich, Heurista

Hubka, V., \& Eder, W.E. (1996) Design Science: Introduction to the Needs, Scope and Organization of Engineering Design Knowledge, London: SpringerVerlag, http://deseng.ryerson.ca/DesignScience/, completely revised edition of Hubka, V. and Eder, W.E. (1992) Einführung in die Konstruktionswissenschaft (Introduction to Design Science), Berlin, SpringerVerlag

ISO9000:2000 (2000) Quality Management Systems Fundamentals and Vocabulary, Geneva: ISO

ISO 14001:1995 (1995) Environmental Management System, Geneva: ISO

Klaus, G. (1965) Kybernetik in philosophischer Sicht (Cybernetics in Philosophical View) 4th ed., Berlin: Dietz Verlag

Koen, B.V. (2003) Discussion of The Method: Conducting the Engineer's Approach to Problem Solving, New York: Oxford Univ. Press

Kuhn, T.S. (1970) The Structure of Scientific Revolutions (2 ed.), Chicago: U. of Chicago Press

Kuhn, T.S. (1977) The Essential Tension: Selected Studies in Scientific Tradition and Change, Chicago: Univ. of Chicago Press

Müller, J. (1990) Arbeitsmethoden der Technikwissenschaften - Systematik, Heuristik, Kreativität (Working Methods of Engineering Sciences, systematics, heuristics, creativity), Berlin: Springer-Verlag

Müller, J. (1991) 'Akzeptanzbarrieren als berechtigte und ernst zu nehmende Notwehr kreativer Konstrukteure nicht immer nur böser Wille, Denkträgheit oder alter Zopf' (Acceptance Barriers as Justified and Serious Defence Reaction of Creative Designers - not always Ill Will, Thinking Inertia or Old Hat), in Hubka, V. (ed.) (1991) WDK 20: Proc. of ICED 91 Zürich, Zürich: Heurista, p. 769-776; and 'Acceptance Barriers as Justified and Serious Defence Reaction of Creative Designers - not always only Ill Will, Thinking Inertia or Old Hat,' in [Eder 1996], 1996, p. 79-84

Müller, J. (1994) 'Akzeptanzprobleme in der Industrie, ihre Ursachen und Wege zu ihrer Überwindung'
(Acceptance Problems in Industry, their Causes, and Ways to Overcome them), in [Pahl 1994a], p. 247-266

G. Pahl (ed.) (1994a) Psychologische und Pädagogische

Fragen beim methodischen Konstruieren:

Ergebnisse des Ladenburger Diskurses vom Mai

1992 bis Oktober 1993 (Psychological and Pedagogic Questions in Systematic Designing: Results of a Discourse at Ladenburger from May 1992 to October 1993), Köln: Verlag TÜV

Pahl, G. (scientific director) (1994b), 'Ergebnisse der Diskussion' (Results of the Discussions), in [Pahl 1994a], p. 1-37

Pahl, G. (1996) 'Transfer Ability as Educational Goal Results of a Discourse at Ladenburg', in [Eder 1996], p. 133-138; and Hubka, V. (ed.) (1995) WDK 23 - Proc. International Conference on Engineering Design ICED 95 Praha, Zürich, Heurista, p. 247-252

Pahl, G., Beitz, W., Feldhusen, J. and Grote, H-K. (2007) Engineering Design ( 3 ed.), London: Springer-Verlag (1 ed. 1984) (Edited and translated by K. Wallace and L. Blessing), translated from 2003-5th ed. of Pahl, G. and Beitz, W., Feldhusen, J. and Grote, H-K. (2007) Konstruktionslehre, Methoden und Anwendungen, (7 ed.) Berlin/Heidelberg: Springer-Verlag (1 ed. 1977)

Schön, D.A. (1983) The Reflective Practitioner: How Professionals Think in Action, Basic Books, New York

Schön, D.A. (1987) Educating the Reflective Practitioner: Towards a New Design for Teaching and Learning in the Professions, San Francisco: Jossey-Bass

Sheldon, D. (1997) 'Does Industry Understand and Adopt Design Science and Tools,' unpublished paper presented at ICED 97 Tampere [Riitahuhta, A. (ed.) (1997) WDK 25 - Proc. ICED 97 Tampere, Tampere University]

Wallas, G. (1926) The Art of Thought, London: Cape (reprint 1931) - p. 79-96 reprinted in Vernon, P.E. (ed.) (1970) Creativity, Harmondsworth: Penguin, p. 91-97

W. Ernst Eder, MSc, PEng

Professor Emeritus, Dr.h.c. (University of West Bohemia in Pilsen, Czech Republic)

Royal Military College of Canada, Department of Mechanical Engineering (retired)

Home Address: 107 Rideau Street, Kingston, Ontario, Canada K7K 7B2

Phone: x-1-613-547-5872

Email: eder-e@kos.net 